\title{
CHEMOSPHERE
}

\section{A case study of molinate application in a Portuguese rice field: herbicide dissipation and proposal of a clean-up methodology}

\author{
Marisa Castro a , António C. Silva-Ferreira ${ }^{\mathrm{a}}$, \\ Célia M. Manaia a , Olga C. Nunes ${ }^{b, *}$ \\ ${ }^{a}$ Escola Superior de Biotecnologia, R. Dr. António Bernardino de Almeida, 4200-072 Porto, Portugal \\ ${ }^{\mathrm{b}}$ LEPAE-Departamento de Engenharia Química, Faculdade de Engenharia, Universidade do Porto, \\ R. Dr. Roberto Frias, 4200-465 Porto, Portugal
}

Received 4 June 2004; received in revised form 4 October 2004; accepted 17 November 2004

\begin{abstract}
This study was designed to monitor molinate losses in surface and underground waters during Ordram application in a rice field situated in central Portugal. Water samples were collected from different sites, before, during and about one month and a half after Ordram application. Molinate quantification was based on a solid-phase microextraction (SPME) method followed by gas chromatography with flame photometric detector (GC-FPD) analysis, and led to the conclusion that the herbicide was dissipated in the environment, reaching levels as high as $3.9 \mu \mathrm{g} 1^{-1}$ in underground water and $15.8 \mu \mathrm{g} 1^{-1}$ in the river receiving tail waters. The feasibility of the application of treatment methodologies based on adsorption or biodegradation as processes to remove molinate from real-world waters was assessed. These methods seem suitable to reduce molinate concentrations to values in the range of the legally recommended limits $\left(<0.5 \mu \mathrm{g} 1^{-1}\right)$.
\end{abstract}

(c) 2004 Elsevier Ltd. All rights reserved.

Keywords: Molinate; Environmental contamination; Removal

\section{Introduction}

Molinate ( $S$-ethyl $N, N$-hexamethylene-1-carbamate) is the active ingredient in the commercial herbicide Ordram. This herbicide is applied once a year to flooded fields during rice seeding to control the overgrowth of weeds. The modes and extent of molinate dissipation

\footnotetext{
* Corresponding author. Tel.: +351 22 5081917; fax: +35122 5081449.

E-mail address: opnunes@fe.up.pt (O.C. Nunes).
}

in rice fields were described before by Soderquist et al. (1977), who showed that volatilization represents $75-85 \%$ of the total losses, with photolysis and soil adsorption contributing less than $20 \%$. According to Soderquist et al. (1977) the levels of molinate reaching underground waters would be negligible and readily eliminated by microbiota and plant metabolism. Nevertheless, other studies alerted for the presence of trace amounts of molinate in surface, ground and underground waters in California (USA), Australia, Japan, Greece, Spain and Portugal (Julli and Krassoi, 1995; Mabury et al., 1996; Albanis et al., 1998; Tsuda et al., 
1998; Hernandez et al., 2000; Cerejeira et al., 2003), strongly suggesting the dispersion of this herbicide, eventually through leaching. Factors such as soil characteristics, climate conditions (as temperature, humidity, wind, rain, among others), and agricultural practices may influence the dissipation of organic pollutants in the environment, making the ways of dispersion specific for each region. For this reason, it was considered relevant to follow the molinate dispersion during its application in the rice fields in central Portugal. This was the major objective of the present work.

Water samples, collected at three different stages during rice fields treatment, were analysed for molinate content. It was observed that surface and underground waters were contaminated with molinate at levels above $0.5 \mu \mathrm{g} 1^{-1}$, which is the upper value recommended by the environmental quality objectives for surface waters (Decreto-Lei 236/98). Considering those results, the feasibility of adsorption or biodegradation as methodologies to treat these real world waters contaminated with molinate was assessed.

\section{Experimental}

\subsection{Sampling}

Water samples were collected within a period of 3 months, in a rice field ("Quinta do Seminário") situated in the valley of river Pranto, a tributary of river Mondego (Vinha da Rainha, Soure, Portugal). Localisation and soil characteristics of the studied rice field are presented, respectively, in Fig. 1 and Table 1. This rice field of 70 ha has a history of molinate application of about 30 years. Ordram, a granular compound containing $7.5 \%$ molinate, has been applied once a year at a rate of $40-60 \mathrm{~kg} \mathrm{ha}^{-1}$. Sampling schedule comported three distinct periods of the spring of 2002: (1) during field preparation for rice seeding (March 26); (2) during rice seedling (May 8); and (3) during crop final treatment (June 19). This final sampling included the collection of water from river Pranto, in a site of discharge of tail waters from different paddy rice fields situated in the valley of this river (Amieira bridge), situated at about $5 \mathrm{~km}$ downstream from the sampled field (Fig. 1a). A volume of 11 of each water sample was collected for a tightly sealed pyrex flask, transported with refrigeration and stored at $-30{ }^{\circ} \mathrm{C}$ until its analysis. The schematic representation of sampled area is illustrated in Fig. $1 \mathrm{~b}$.

\subsection{Molinate extraction and analysis}

Molinate was extracted using solid-phase microextraction (SPME), a methodology that has been widely used to quantify molinate in environmental samples
(Aguilar et al., 1998; Penalver et al., 1999; Hernandez et al., 2000; Lambropoulou et al., 2002). The herbicide was quantified by gas-chromatography using a flame photometric detector (FPD). Manual extraction was performed using a holder assembly and replaceable fiber assemblies. SPME was conducted in $10 \mathrm{ml}$ sealed vials containing $5 \mathrm{ml}$ of sample with $200 \mathrm{gl}^{-1}$ of sodium sulphate, and the internal standards 3-octanol at $191 \mu \mathrm{g}^{-1}$, and ethylmethyl-thioacetate at a concentration of $40.8 \mu \mathrm{g}{ }^{-1}$. Extraction was carried out by fiber immersion in the liquid phase for $30 \mathrm{~min}$ at room temperature (by immersion of the vial in tap water) with constant magnetic stirring at $500 \mathrm{rpm}$. Initially, three different mixed-coating fibers - carboxen/polydimethylsiloxane (CAR/PDMS), dininylbenzene/polydimethylsiloxane (DVB/PDMS) and dininylbenzene/carboxen/ polydimethylsiloxane (DVB/CAR/PDMS) (Supelco, Bellefonte, USA), were tested by quantifying molinate using a $5.0 \mu \mathrm{g}^{-1}$ standard solution. The SPME recovery of fiber assemblies was calculated based on the analysis of six samples of ultra-pure water spiked individually. Based on the results presented in Table 2, the DVB/CAR/PDMS fiber assembly was selected for further analysis.

For chromatographic analysis, fiber assembly was inserted into the injection port of the gas chromatograph for $10 \mathrm{~min}$, being the extracted chemicals desorbed thermally and transferred directly to the analytical column. To prevent contamination, fiber assemblies were cleaned before each extraction, by insertion in the injection port at $220^{\circ} \mathrm{C}$ for $30 \mathrm{~min}$. Chromatographic analysis were performed using a Hewlett-Packard 5890 (Palo Alto, CA, USA) equipped with a flame photometric detector (FPD) and a flame ionization detector (FID), both used to analyse the samples, although only FPD was used for quantification. The chromatographic column used was as described before (Barreiros et al., 2003). The temperature program was: $40^{\circ} \mathrm{C}(1 \mathrm{~min})$, then $3{ }^{\circ} \mathrm{C} \mathrm{min}^{-1}$ to $220^{\circ} \mathrm{C}$. The splitless time was $2.0 \mathrm{~min}$. The carrier gas was $\mathrm{H}_{2}$ at a flow rate of $1.2 \mathrm{ml} \mathrm{min}{ }^{-1}$. The FPD used hydrogen at $50 \mathrm{ml} \mathrm{min}{ }^{-1}$ and a mixture of nitrogen/oxygen $(80 / 20)$ at $70 \mathrm{ml} \mathrm{min}^{-1}$, using as the make-up gas nitrogen at $70 \mathrm{ml} \mathrm{min}^{-1}$. FID conditions were as described previously (Barreiros et al., 2003). Gas chromatography-mass spectrometry (GC/MS) analysis was performed as described previously (Barreiros et al., 2003). Molinate chromatographic peak was identified by comparison with real standards; mass spectrometry was used to confirm the identification and the presence of the herbicide in environmental samples.

Environmental samples were analysed using the above described procedure. A calibration curve was obtained using molinate aqueous solutions with concentrations ranging from 0.5 to $20 \mu \mathrm{g}^{-1}$, and was well adjusted by a second order polynomial model [Concentration $=-0.1006 \times(F)^{2}+0.1213 \times(F)+1.3341$, where 


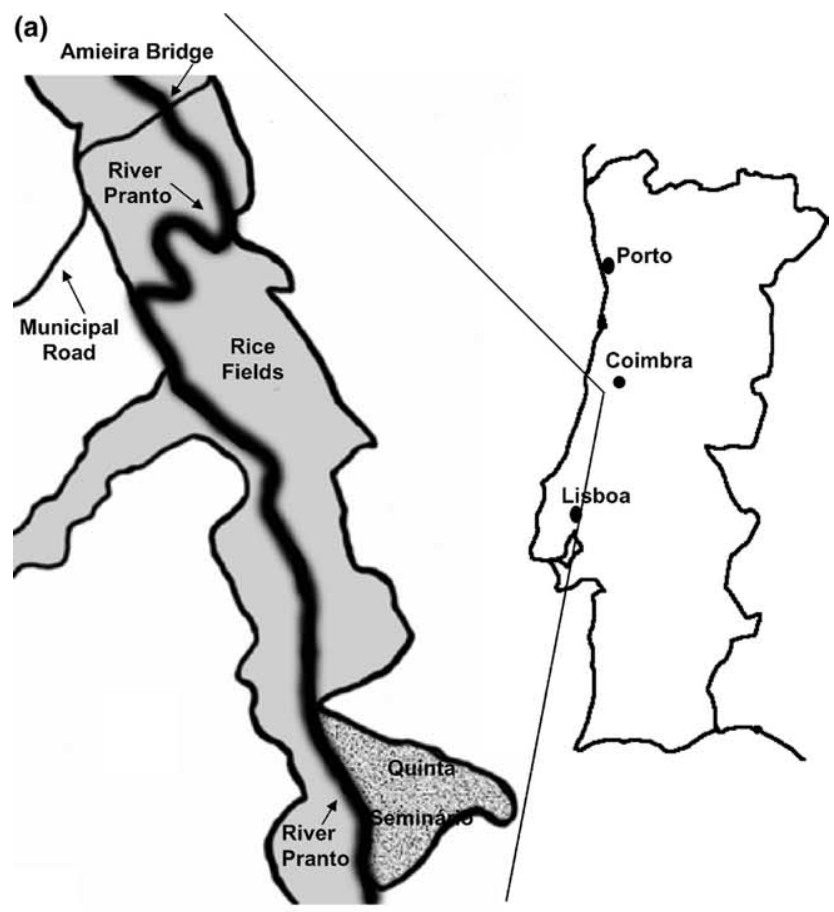

(b)

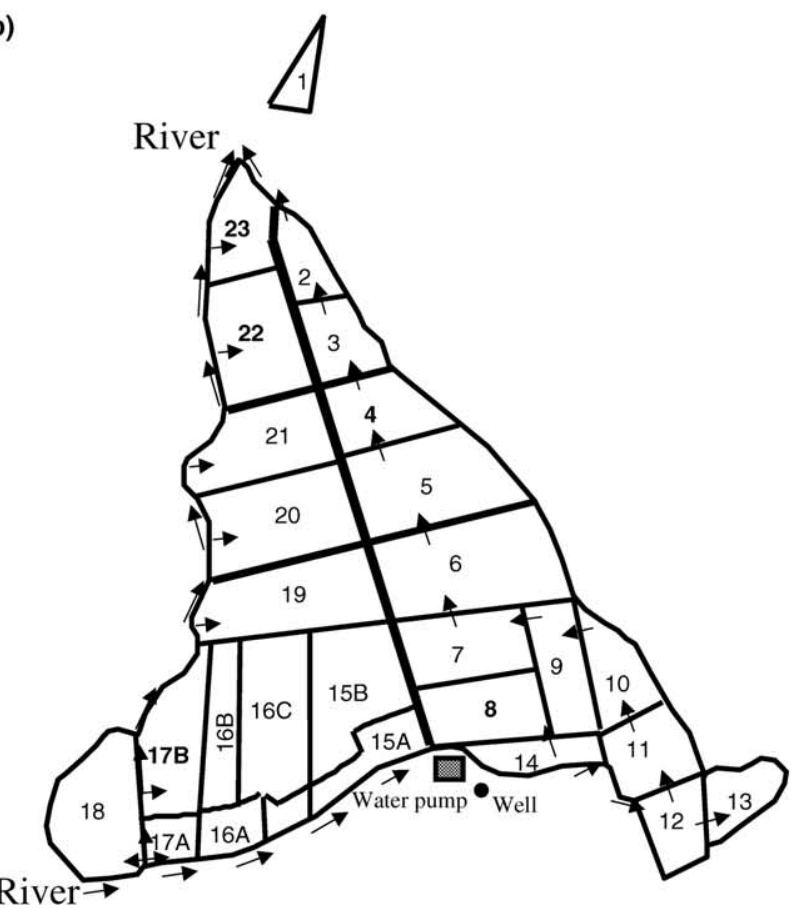

Fig. 1. (a) Schematic representation of the localisation of the studied area at the valley of river Pranto. Shadowed area represents rice fields, including "Quinta do Seminário". Geographic co-ordinates of the area: $40^{\circ} 01^{\prime} \mathrm{N}, 8^{\circ} 41^{\prime} \mathrm{W}$. (b) Schematic representation of the rice field ("Quinta do Seminário"). The numbers indicate the plots (bold numbers correspond to sampled plots). Arrows indicate the water flow from river to the field and within the field. Please note that all plots on the left side of the field and plots 12 and 14 on the right side are irrigated with waters from the river. The irrigation in right side of the field is made serially, with water reaching plot 2 being drained through all upstream plots. 
Table 1

Physical-chemical properties of the rice field soil

\begin{tabular}{ll}
\hline Soil texture & \\
Sand & $67 \%$ \\
Silt & $19 \%$ \\
Clay & $14 \%$ \\
Physical-chemical analysis & \\
pH & 5.8 \\
Electric conductivity & $0.3(\mathrm{~m} \Omega / \mathrm{cm})$ \\
Total organic matter & $1.17 \%$ \\
Total nitrogen & $0.07 \%$ \\
Total organic carbon & $0.68 \%$ \\
Carbon/nitrogen ratio & 9.7 \\
\hline
\end{tabular}

A total of four soil samples were analysed by Fitosoil, Centro de Agroanalisis, San Gines, Murcia, Spain, on January 2000.

Table 2

Percentage of recovery, limit of detection and precision of molinate quantification for different fibers

\begin{tabular}{lllc}
\hline Fiber & Recovery $(\%)$ & LOD $\left(\mu \mathrm{g}{ }^{-1}\right)^{\mathrm{a}}$ & RSD $(\%)^{\mathrm{b}}$ \\
\hline PDMS/DVB & 90.9 & 2.83 & 8.1 \\
CAR/PDMS & 79.6 & 5.21 & 12.3 \\
CAR/PDMS/DVB & 97.7 & 0.48 & 9.1 \\
\hline
\end{tabular}

${ }^{a}$ Limit of detection, determined as the amount of analyte required to give a signal-to-noise ratio of 3 (Silva Ferreira et al., 2003).

b Relative standard deviation, of five consecutive replicates.

$F=\log$ (area of molinate/area of internal standard)], being observed a correlation coefficient $(r)$ of 0.9994 . Whenever necessary, environmental water samples were diluted in order to fit the dynamic linearity range. Samples were analysed in duplicate or triplicate.

In order to assess molinate contamination in snails living in the area (collected nearby the water pump), the herbicide was extracted using a modification of the above mentioned method. The headspace of an aqueous suspension containing the correspondent to a dry weight of $25 \mathrm{~g}$ to $100 \mathrm{~g} \mathrm{l}^{-1}$ of homogenised snails, was extracted, by SPME, for $60 \mathrm{~min}$. at $45^{\circ} \mathrm{C}$. Experimental data was interpolated in a calibration curve obtained with molinate aqueous solutions extracted similarly. The detection limit was estimated to be $1.6 \mu \mathrm{g} 1^{-1}$.

\subsection{Molinate removal from real-world waters}

Volumes of $20 \mathrm{ml}$ of water samples were inoculated with a pre-culture of a bacterial mixed culture, named DC as described previously (Barreiros et al., 2003), in order to reach an initial cell density of approximately $50 \mathrm{mg}^{-1}$. The pre-culture was grown in culture medium B (Barreiros et al., 2003) with $750 \mathrm{mg}^{-1}$ molinate and incubated in $100 \mathrm{ml}$ Erlenmeyer flasks, at $30^{\circ} \mathrm{C}$, $120 \mathrm{rpm}$ for 3 days. For molinate adsorption assays, bacterial inocula was replaced by $0.09 \mathrm{~g}$ (dry weight) of adsorbent, activated carbon (NORIT GAC 1240 PLUS) or resin Amberlite XAD-4, as described earlier (Silva et al., 2004), maintaining the remaining experimental settings. Molinate content was analysed in liquid phase at the end of the incubation or contact period. Controls, where distilled water was added instead of bacterial culture or adsorbent, were incubated and analysed similarly.

\section{Results and discussion}

\subsection{Molinate dissipation}

The first samples were collected about 1 year (March 26) after the last Ordram application, when rice fields were being prepared for new seeding. At this stage, the water was being drained from the soil, pumped up to about $2 \mathrm{~m}$ high, and flowed out to a water reservoir; the aerated water re-circulated through the field. Sampling included the drainage water system, in the water curtain, and a covered well located nearby the water pump (Fig. 1b), with $4 \mathrm{~m}$ depth. The detection of molinate in both samples at concentrations above $0.5 \mu \mathrm{g} 1^{-1}$, the upper value recommended by the environmental quality objectives for surface waters for individual pesticides in surface waters (Decreto-Lei 236/98) (Table 1), is indicative of its persistence in the environment. Furthermore, the higher levels of molinate found in the well may suggest that the herbicide is leached to underground waters, where it is accumulated for long periods, being, eventually, also responsible for the contamination detected in the drainage waters. In fact, the risk of ground water contamination by molinate has been explained based on its simultaneous poor adsorption to soil (adsorption coefficient of 190) and high water solubility $\left(880 \mathrm{mg}^{-1}\right)$, which facilitate the mobility of this herbicide in the environment (Wauchope et al., 1992).

Rice seedlings were transplanted in late April to the paddy fields (flood depth of about $10 \mathrm{~cm}$ ), where the herbicide had been applied with a farm tractor. Herbicide application followed the temporal sequence described in Table 3. At this stage (May 8), the molinate concentration in paddy and drainage waters of "Quinta do Seminário" was in the same range of those found on other rice fields in USA (Soderquist et al., 1977; Deuel et al., 1978) or irrigation channels in Spain (Jiménez et al., 1999) on equivalent periods of rice crop treatment. The differences of molinate concentrations found in the present study throughout different plots can be easily explained by the time elapsed between each application and sampling (Table 3). These results evidence the readily dissipation of molinate and could be expected according to previous studies which report a half-life of molinate in paddy water under field conditions of 3-10 
Table 3

Ordram application schedule and molinate quantification in environmental samples

\begin{tabular}{|c|c|c|c|c|c|c|}
\hline \multirow[t]{2}{*}{ Sampling site } & \multirow[t]{2}{*}{ Area (ha) } & \multirow{2}{*}{\multicolumn{2}{|c|}{$\begin{array}{l}\text { Ordram applied }(\mathrm{kg}) \\
\text { and date of application }\end{array}$}} & \multicolumn{3}{|c|}{ Molinate $\left(\mu \mathrm{g} \mathrm{1^{-1 } )}\right.$} \\
\hline & & & & March 26 & May 8 & June 19 \\
\hline River & - & - & - & - & - & 15.8 \\
\hline Water curtain & - & - & - & 0.7 & 220.6 & 18.7 \\
\hline Well & - & - & - & 3.9 & 476.6 & 10.9 \\
\hline Plot 22 & 4.03 & 161 & April 29 & - & 93.9 & 18.2 \\
\hline Plot 23 & 2.18 & 87 & April 29 & - & 124.8 & 19.1 \\
\hline Plot 17B & 1.90 & 116 & May 2 & - & 256.3 & 16.1 \\
\hline Plot 8 & 3.00 & 120 & May 4 & - & 271.9 & 199.3 \\
\hline Plot 4 & 2.27 & 90 & May 8 & - & 1570.0 & 722.4 \\
\hline
\end{tabular}

Values are the mean of two or three independent analysis; relative standard deviations (\% RSD) obtained ranged between 1.3 and 8.9 .

days (Deuel et al., 1978; Ross and Sava, 1986; Johnson and Lavy, 1995; Mabury et al., 1996).

After transplantation of rice seedlings, the flooded paddies rested for about 20 days. Following this period, fields were drained and the herbicide Stam (propanil, $80 \% \mathrm{w} / \mathrm{w}$ ) and the acidifying agent BB5 were applied at rates of $6 \mathrm{~kg} \mathrm{ha}^{-1}$ and $250 \mathrm{ml} \mathrm{ha}^{-1}$, respectively. Since Stam may have phytotoxic effects in the presence of carbamates it was applied to drained fields. Two days after Stam application fields were flooded again (flood depth of around $10 \mathrm{~cm}$ ) and the herbicide Rancho (bensulfuron-methyl, $0.083 \% \mathrm{w} / \mathrm{w}$, mefenacet $1.25 \% \mathrm{w} / \mathrm{w}$, and molinate, $3.75 \% \mathrm{w} / \mathrm{w}$ ) was applied at a rate of $60 \mathrm{~kg} \mathrm{ha}^{-1}$, following the same temporal sequence as used for Ordram (Table 3). Crop treatment was completed with the application of ammonium sulfate.

When the last sampling was made, on June 19, only plots 22, 23 and 17B had received the complete treatment, including ammonium sulfate. The higher molinate concentrations were detected in plots 8 and 4 , the last receiving Rancho, and not yet amended with ammonium sulphate. The comparatively lower concentrations found in plots 22, 23 and 17B may be due to the increased metabolic activity of autochthonous microbiota, resultant from a stimulation of molinate biodegradation due to the application of ammonium sulfate. In fact, Deuel and collaborators (1978) suggested that biological degradation was the principle mode of molinate dissipation in a field experiment. Another hypothesis to explain the higher levels of molinate found in plots 8 and 4 , is that water irrigating these paddies, is drained through upstream plots, eventually continuously leaching molinate (Fig. 1b). Molinate concentration in rice paddies with complete treatment was about $19 \mu \mathrm{g} 1^{-1}$, a value similar to that found in drained water (water curtain) and in river Pranto. The homogeneity of these concentration values is consistent with the fact that tail waters from this and other rice fields are discharged to the river during crop treatment (Table 3). Higher values were referred by Cerejeira et al. (2003), who quantified levels of molinate above $20 \mu \mathrm{g}^{-1}$ in river Sado, in a rice producing area at south Portugal. The results obtained in the present study, as those of Cerejeira and collaborators, indicate the surface run-off of the herbicide.

One of the major concerns about environmental pesticide contamination is its bio-accumulation and propagation through trophic chain. In order to assess if molinate contamination was restricted to agricultural waters during application period or if it was extended besides that barrier, molinate was analysed in autochthonous snails collected prior (March 26) and after (June 19) the herbicide application. In snails collected after molinate application, the herbicide concentration was estimated to be around $3 \mu \mathrm{g} \mathrm{g}^{-1}$ dry weight (equivalent to $73.8 \mu \mathrm{g} 1^{-1}$ in a suspension of snails homogenate containing $0.25 \mathrm{~g}$ dry weight), being bellow the detection limit in snails collected before rice fields treatment. Although additional data, namely about the seasonal variations of the level of molinate contamination, will bring new insights into this subject, these results suggest that molinate environmental dispersion represents a risk for trophic chain contamination. A similar conclusion was reported by Tsuda and collaborators (1998) who showed that it was possible to estimate a relationship between the extent of molinate contamination of river waters and of different fish species.

Several authors studied the dissipation of molinate both in rice fields and using laboratory or glasshouse experiments (Soderquist et al., 1977; Deuel et al., 1978; Imai and Kuwatsuka, 1982, 1988; Ross and Sava, 1986; Johnson and Lavy, 1995; Konstantinou et al., 2001), although this last approach has evident bias, which limit the interpretation of field data. In the present work, the highest molinate concentrations were observed in the day of Ordram application and following days. Molinate contamination of surface (rivers, irrigation channels) (Albanis et al., 1998; Jiménez et al., 1999; Cerejeira et al., 2003) or underground waters (Albanis et al., 1998) is maximal shortly after the herbicide application on rice fields, decreasing throughout summer, becoming undetectable during winter. Such results are in agreement with previous studies which refer a 
Table 4

Molinate concentration $\left(\mu \mathrm{g} \mathrm{l}^{-1}\right)$ after treatment of real-world waters by biodegradation or adsorption

\begin{tabular}{lcccc}
\hline Sample & Control & Biodegradation & \multicolumn{2}{l}{ Adsorbent } \\
\cline { 3 - 5 } & & & GAC & Amberlite \\
\hline Well (May 8) & 476.0 & 0.6 & $<0.48$ & $<0.48$ \\
Plot 4 (May 8) & 1550.0 & 2.2 & $<0.48$ & $<0.48$ \\
Plot 8 (June 19) & 193.7 & $<0.48$ & $<0.48$ & $<0.48$ \\
Plot 17B (June 19) & 10.5 & $<0.48$ & $<0.48$ & $<0.48$ \\
\hline
\end{tabular}

rapid molinate dissipation of rice fields paddy waters, mainly by volatilization (Soderquist et al., 1977; Ross and Sava, 1986). Other processes such as photodegradation, microbial degradation, soil adsorption, biota incorporation, leaching and surface run-off may contribute also for molinate losses (Soderquist et al., 1977; Deuel et al., 1978; Imai and Kuwatsuka, 1982, 1988; Ross and Sava, 1986; Carrasco et al., 1992; Johnson and Lavy, 1995; Albanis et al., 1998; Tsuda et al., 1998; Hernandez et al., 2000; Konstantinou et al., 2001; Cerejeira et al., 2003). However, under field conditions, numerous factors may influence the extent and contribution of each dissipation mode. For example, in water, the association of molinate with soil constituents and/or organic matter, namely colloidal suspensions and microbial biomass, may reduce the extent of both volatilization (Deuel et al., 1978) and photodegradation (Konstantinou et al., 2001). It has been referred that, although small, the fraction of molinate adsorbed to soil persists under flooded, and declines in drained fields conditions (Soderquist et al., 1977; Ross and Sava, 1986), probably due to microbial degradation (Imai and Kuwatsuka, 1982, 1988) or photodegradation (Konstantinou et al., 2001). Nevertheless, in the present study the detection of molinate in the well and in the water curtain after almost one year, since the last application of molinate, may indicate that under field conditions such herbicide dissipation, processes are not enough to remove this pollutant to levels below those legally recommended.

\subsection{Molinate removal from real-world waters}

Considering the levels of molinate contamination found, the usefulness of molinate removal methods developed previously (Barreiros et al., 2003; Silva et al., 2004) to decontaminate natural waters containing low concentrations of molinate was assessed. With this purpose, duplicates of four samples of real-world waters containing between 11 and $1550 \mu \mathrm{g} \mathrm{l}^{-1}$ of the herbicide were treated by a biological and a physical procedure in order to evaluate the extent of molinate removal (Table 4). Molinate biodegradation was tested using a five member bacterial mixed culture (DC) previously described as able to mineralize molinate, without the accumulation of degradation products, in culture medium with relatively high herbicide concentrations, (187-750 $\mathrm{mg} \mathrm{l}^{-1}$ ) (Barreiros et al., 2003). In the present study, it was intended to determine if low concentrations of herbicide and/or the presence of inhibitors, such as the components of Stam and Rancho, in agricultural waters could limit or inhibit herbicide degradation. Molinate was reduced, to concentrations close to the detection limit, demonstrating that molinate bioavailability for mixed culture DC, in realworld waters, is near the legally recommended limits. The fact that in waters containing higher molinate concentrations, the herbicide was not completely removed may be due to a limiting nutrient when longer periods of incubation are required. Despite the high efficacy of mixed culture DC to degrade molinate, the dispersion of biological agents in the environment is not allowed nor desirable, being necessary a prior removal of the herbicide using a physical method such as adsorption. In a previous study, GAC and resin Amberlite XAD-4 were observed to be very efficient adsorbents for molinate (Silva et al., 2004). The usefulness of such adsorbents to remove low concentrations of molinate in the presence of potential competitors for adsorption was also tested in the real-world waters. The results obtained (Table 4) show that molinate was removed by resin Amberlite XAD-4 or GAC to levels below the detection limit.

The results obtained throughout this study, indicated that molinate concentration in drainage system should be reduced in order to minimise the contamination of distant areas such as rivers, wells, or even the aquifer. One useful approach may be the implementation of adequate treatment systems to clean canal waters. Considering the results obtained in this study, the use of an adsorption based methodology to clean in situ molinate contaminated drainage waters before discharge into the river could be successfully implemented. As showed in a previous study (Silva et al., 2004), the bioregeneration of the adsorbents can also be implemented using mixed culture DC, which based on the present study maintain capacity to degrade the herbicide in real-world waters.

\section{Conclusions}

The results obtained during this study showed that the use of molinate in a rice field crop led to environmental contamination. Despite of the rapid dissipation from waters, the period during which molinate persists in the 
environment is enough to be leached to surface and underground waters and to contaminate the trophic chain.

The feasibility of the utilisation of physical and biological methods as processes to remove molinate from real-world waters was assessed. Molinate content was reduced to values in the range of the legally recommended limits $\left(<0.5 \mu \mathrm{g}^{-1}\right)$ both by adsorption, on to activated carbon or onto resin Amberlite XAD-4, and by biodegradation with a bacterial mixed culture (DC) previously reported as capable of molinate mineralisation. It is proposed that such methodologies could be successfully implemented in future, to clean in situ molinate contaminated drainage waters before discharge in to the natural water streams, in order to avoid environmental contamination.

\section{Acknowledgments}

Authors gratefully acknowledge Maria de Fátima Barroso, Luísa Barreiros and Cláudia Coelho for technical assistance, and Sr. António Carriço, owner of "Quinta do Seminário", who permitted the sampling of the real-world waters and gave all the information concerning the rice agricultural procedure. This work was financially supported by Fundação para a Ciência e a Tecnologia from Ministério da Ciência e do Ensino Superior, Portugal through FEDER funds (projects POCTI/12193/1998 and POCTI/34274/AGR/2000).

\section{References}

Aguilar, C., Penalver, S., Pocurull, E., Borrull, F., Marcé, R.M., 1998. Solid-phase microextraction and gas chromatography with mass spectrometric detection for the determination of pesticides in aqueous samples. J. Chromatogr. A $795,105-115$.

Albanis, T.A., Hela, D.G., Sakellarides, T.M., Konstantinou, I.K., 1998. Monitoring of pesticide residues and their metabolites in surface and underground waters of Imathia (N. Greece) by means of solid-phase extraction disks and gas chromatography. J. Chromatogr. A 823, 59-71.

Barreiros, L., Nogales, B., Manaia, C.M., Silva-Ferreira, A.C., Pieper, D.H., Reis, M.A., Nunes, O.C., 2003. A novel pathway for mineralization of the thiocarbamate herbicide molinate by a defined bacterial mixed culture. Environ. Microbiol. 5, 944-953.

Carrasco, J.M., Sabater, C., Alonso, J.L, Gonzalez, J., Botella, S., Amoros, I., Ibanex, M.J., Boira, H., Ferrer, J., 1992. Molinate decontamination processes in effluent water from rice fields. Sci. Total Environ. 123/124, 219-232.

Cerejeira, M.J., Viana, P., Batista, S., Pereira, T., Silva, E., Valerio, M.J., Silva, A., Ferreira, M., Silva-Fernandes, A.M., 2003. Pesticides in Portuguese surface and ground waters. Water Res. 37, 1055-1063.
Decreto-Lei 236/98, 1 August 1998. Anexo XXI, Objectivos ambientais de qualidade mínima para as águas superficiais; Diário da República, série I-A, no.; 176/98, 3676.

Deuel, L.E., Turner, F.T., Brown, K.W., Price, J.D., 1978. Persistence and factors affecting dissipation of molinate under flooded rice culture. J. Environ. Qual. 7, 373-377.

Hernandez, F., Beltran, J., Lopez, F.J., Gaspar, J.V., 2000. Use of solid-phase microextraction for the quantitative determination of herbicides in soil and water samples. Anal. Chem. 72, 2313-2322.

Imai, Y., Kuwatsuka, S., 1982. Degradation of the herbicide molinate in soils. J. Pestic. Sci. 7, 487-497.

Imai, Y., Kuwatsuka, S., 1988. Residues of the herbicide molinate and its degradation products in pot soil and rice plants. J. Pestic. Sci. 13, 247-252.

Jiménez, B., Moltó, J.C., Font, G., Soriano, J.M., 1999. Evaluation by HPLC-UV of polar pesticides in rice fields. Bull. Environ. Contam. Toxicol. 63, 813-820.

Johnson, W.G., Lavy, T.L., 1995. Organic chemicals in the environment. Persistence of carbofuran and molinate in flooded rice culture. J. Environ. Qual. 24, 487-493.

Julli, M., Krassoi, F.R., 1995. Acute and chronic toxicity of the thiocarbamate herbicide, molinate, to the Cladoceran Moina australiensis Sars. Bull. Environ. Contam. Toxicol. 54, 690-694.

Konstantinou, I.K., Zarkadis, A.K., Albanis, T.A., 2001. Photodegradation of selected herbicides in various natural waters and soils under environmental conditions. J. Environ. Qual. 30, 121-130.

Lambropoudou, D.A., Konstantinou, I.K., Albanis, T.A., 2002. Factors affecting multiresidue determination of priority herbicides when using solid-phase microextraction. J. AOAC Int. 85, 486-493.

Mabury, S.A., Cox, J.S., Crosby, D.G., 1996. Environmental fate of rice pesticides in California. Rev. Environ. Contam. Toxicol. 147, 71-117.

Penalver, A., Pocurull, E., Borull, F., Marcé, R.M., 1999. Evaluation of parameters in solid-phase microextraction process. Chromatographia 50, 685-688.

Ross, L.J., Sava, R.J., 1986. Fate of thiobencarb and molinate in rice fields. J. Environ. Qual. 15, 220-224.

Silva Ferreira, A.C., Hogg, T., Guedes de Pinho, P., 2003. Key odorants of oxidative spoiled white wines. J. Agric. Food Chem. 51, 1377-1381.

Silva, M., Fernandes, A., Manaia, C.M., Mendes, A., Nunes, O.C., 2004. Preliminary feasibility study for the use of an adsorption/bio-regeneration system for molinate removal from effluents. Water Res. 38, 2677-2684.

Soderquist, C.J., Bowers, J.B., Crosby, D.G., 1977. Dissipation of molinate in a rice field. J. Agric. Food. Chem. 25, 940945.

Tsuda, T., Kojima, M., Harada, H., Nakajima, A., Aoki, S., 1998. Pesticides and their oxidation products in water and fish from rivers flowing into lake Biwa. Bull. Environ. Contam. Toxicol. 60, 151-158.

Wauchop, R.D., Buttler, T.M., Hornsby, A.G., AugustijinBackers, J.P., Burt, J.P., 1992. The SCR/ARS/CES pesticide properties database for environmental decision making. Rev. Environ. Contam. Toxicol. 123, 1-164. 